\title{
Cognitive Processes Underlying the Artistic Experience
}

\author{
Alejandra Wah \\ Department of Arts, Culture, and Media Studies \\ University of Groningen, the Netherlands \\ a.wah.laborde@rug.nl
}

Received 31 July 2016; accepted 14 January 2017.

\begin{abstract}
Based on the field of aesthetics, for centuries philosophers and more recently scientists have been concerned with understanding the artistic experience focusing on emotional responses to the perception of artworks. By contrast, in the last decades, evolutionary biology has been concerned with explaining the artistic experience by focusing on the cognitive processes underlying this experience. Up until now, the cognitive mechanisms that allow humans to experience objects and events as art remain largely unexplored and there is still no conventional use of terms for referring to the processes which may explain why the artistic experience is characteristically human and universal to human beings (Dissanayake, 1992, p. 24; Donald, 2006, p. 4). In this paper, I will first question whether it is productive to understand the artistic experience in terms of perception and emotion, and I will subsequently propose a possible alternative explanation to understand this experience. Drawing upon the work of Ellen Dissanayake (1992, 2000, 2015), Merlin Donald (2001, 2006, 2013), Antonio Damasio (1994, 2000, 2003, 2010), Barend van Heusden (2004, 2009, 2010), and Alejandra Wah (2014), I will argue that this experience is characterized by particular degrees of imagination and consciousness.
\end{abstract}

Keywords: artistic experience; aesthetics; emotion; perception; imagination; consciousness; meaning; reflective imagination. 


\section{Introduction}

In December 2015, the Center for Mind, Brain and Consciousness at New York University organized a debate, involving Gabrielle Starr and Alva Noë, on the question "Can neuroscience help us understand art?"1 In this debate, Starr and Noë discuss the artistic experience from the perspective of aesthetics and focus on the formal characteristics of specific institutional artworks. For instance, Noë refers to a poem of Walt Whitman and two sculptures by Auguste Rodin and Constantin Brancusi whereas Starr mentions her research on poetical genres such as the sonnet and the haiku. I would like to join this debate drawing upon my presentation given in the international workshop KNEW 2015 Placing Art and Music in Nature in Kazimierz Dolny, Poland in November 2015, that is, one month before this debate took place.

In this paper I question whether it is productive to think about art in terms of perception and emotion. To question this is important because up until now aesthetic accounts have not fully explained the artistic experience. I argue that the artistic experience is characterized by a specific human cognitive strategy that combines particular degrees of imagination and consciousness, which I refer to as reflective imagination (Wah, 2014). This cognitive strategy can be triggered by the experience of not only institutional artworks but any emotionally competent stimulus whether recalled, perceived, or imagined (Damasio, 2010, pp. 143, 149; Kandel, 2012, p. 313). To conclude, I also offer an answer to the debate's main question. The purpose of this paper is to provide a possible alternative explanation to understand the artistic experience based upon the work of Ellen Dissanayake (1992, 2000, 2015), Merlin Donald (2001, 2006, 2013), Antonio Damasio (1994, 2000, 2003, 2010), Barend van Heusden (2004, 2009, 2010), and Alejandra Wah (2014).

\section{Perception and Emotion}

Based upon the philosophical field of aesthetics, scientists have aimed at explaining the artistic experience focusing on responses to the perception of formal features of objects and events in what is now referred to as empirical aesthetics and neuroaesthetics. At the end of the nineteenth-century, the physicist and philosopher Gustav Fechner (1860, 1876), a pioneer of empirical aesthetics and founder of psychophysics, investigated the relationship between stimuli and perception, and developed methods to quantify sensations. He argued that our sensations are related to physical properties and investigated how features of stimuli such as color, shape, size, proportion, brightness and loudness affect human preferences and please them. In the first half of the twentieth-century, Gestalt psychologists argued further that examining the perception of specific features made the process of perception seem too passive. They postulated that we perceive the world as a whole, and they analyzed principles such as proximity, similarity, closure, and continuation. The Gestalt approach to perception as applied to art reached its peak in the second half of the

\footnotetext{
${ }^{1}$ https://wp.nyu.edu/consciousness/neuroaesthetics/
} 
twentieth-century with studies conducted by psychologist Rudolph Arnheim $(1954,1969)$ who pointed out other formal principles that influence perception such as balance, symmetry, and composition (Chatterjee, 2013, pp. 134-136).

The next major trend in empirical aesthetics was a move from perception towards the role of emotion and attention. Daniel Berlyne (1960), for instance, studied the role of arousal and motivational factors focusing on pleasure, and thought of properties not considered by the Gestalt psychologists such as novelty, surprise, complexity, and ambiguity. Several decades later, and drawing upon the term "neuroaesthetics" coined by Semir Zeki (1999), neuroscientists studied neural underpinnings mediating the perception of judged-beautiful and judged-ugly institutional art basing their research upon neuroimaging methods such as a noninvasive tool sensitive to the location of brain activity (fMRI), a technology which records the duration of brain waves and electrical pulses (MEG), and a method which detects electrical activity in sensorimotor areas, core emotional centers, and reward-related centers (EEG). For example, Kawabata and Zeki asked participants to rate abstract, stilllife, landscape, or portrait paintings as beautiful, neutral, or ugly while their brains were being scanned. They found that activity was greater in the orbitofrontal cortex for stimuli judged as beautiful, and in the motor cortex for stimuli judged as ugly (Kawabata \& Zeki, 2004). Neuroscientists Vilayanur Ramachandran and William Hirstein also related formal principles to what they referred to as art and proposed "eight laws of aesthetic experience." These are peak shift effect, grouping and binding, isolating a single module and allocating attention, reinforcing contrast extraction, perceptual problem solving, abhorrence of unique vantage points, symmetry, and metaphors. They argued that these principles excite the organism optimally, as supernormal stimuli, triggering a high emotional activation which may be partially pre-established in the organism, powerfully stimulating neural mechanisms which mediate perception, and thus functioning as early-warning systems that arrest attention and facilitate the activation of neural patterns vital for survival (Ramachandran \& Hirstein, 1999, pp. 15, 32).

By the end of the twentieth-century, neuroaesthetics had firmly established that the perception of certain formal features of stimuli, mostly of institutional art, may be measured in quantifiable parameters - even if one is not fully aware of those parameters - and that neural patterns underpin emotional responses. However, in the last decade, at least three arguments have been put forward to support the statement that these studies cannot fully explain the artistic experience. First, the neuroimaging techniques and technologies used in these experiments lie at the heart of some of the most pressing and persistent problems in understanding the artistic experience. The manner by which these studies compose and decompose the possible structural aspects of experience has important limitations (Noë, 2009, pp. 20-21; Stafford, 2011, p. 5). For instance, the neuroimaging techniques used in the aforementioned studies do not even offer the possibility of recording activity in certain brain areas and lack a sufficient spatial and temporal resolution (Cela-Conde et al., 2011, p. 46). 
Second, the concept of art is being conceived of in an extremely limited way. In principle, not every person is interested in engaging with institutional art, or with its theoretical discussions, norms, and conventions; and any emotionally competent object or event can potentially afford an artistic experience, as I will explain in the last section. As John Hyman already pointed out when criticizing Ramachandran and Hirstein's theory on the eight principles, these perceptual principles may indeed apply to institutional artworks, but they may also apply to any meaningful stimulus, any emotionally competent object or event that arrests attention (Hyman, 2010, pp. 248-251, 260). Empirical evidence consistently suggests that the emotional response to the perception of formal features of institutional artworks is not different from the emotional response to the perception of formal features of any object or event (Di Dio \& Gallese, 2009, p. 686). Our organism appears to be programmed by evolution to respond emotionally to the perception of significant stimuli automatically and without any conscious awareness of the stimulus or conscious control of the responses (LeDoux, 1996, p. 267). We seem to be predisposed to respond with the activation of neural patterns associated with emotions when we encounter certain formal features. For instance, think of the automatic emotional responses to the perception of certain features of stimuli such as size (as in large animals), large span (as in flying eagles), type of motion (as in reptiles), certain sounds (as in growling), and certain configurations of the body state (as in the pain felt during a heart attack). All these formal features are processed and detected by the limbic system, whose neuron nuclei possess neural dispositions, and trigger the enactment of a body state characteristic of a certain emotion. To know what precisely is causing the pain, or to recognize consciously the bear, the snake, the eagle, or the heart as such is not necessary for an emotional response. The only requirement is that the organism's early sensory cortices detect and categorize the key feature or features of a given entity, and structures such as the amygdala receive signals concerning their presence (Damasio, 1994, p. 131).

Other examples of such emotionally competent formal features are certain organizations of sounds in relation to timbres, pitches, and rhythms, specific kinds of shapes, spatial organizations, and landscapes. A well-known example of landscape-preference is the one that humans find intrinsically pleasurable, one that is similar to the savannas and woodlands of East Africa where hominids split off from chimpanzee lineages, which includes open vistas and proximity to water, vegetation, and evidence of animal and bird life (Dutton, 2009, pp. 43-44). One may also think of the innate preferences for symmetrical faces as a sign of reproductive fitness, the innate ability to read facial expressions, the general tendency towards body adornment, or the general emotional reactions to certain textures, tastes, and smells (Wah, 2014, p. 66). These innate preferences, inclinations, or universal emotional reactions to the perception of certain formal stimuli in all likelihood have survival value and became established in the Pleistocene (Damasio, 2010, p. 295; Dutton, 2009 , p. 30). This means that to study the artistic experience, it appears necessary to consider predetermined universal emotional responses to the perception of certain formal 
features of stimuli in general, and not only of those of objects and events which are institutionally recognized as art. These universal emotional responses must be taken to constitute a first level of meaning, or "universal meaning," in the artistic experience.

Third, their strict focus on beauty, pleasure, visual and auditory images, their search for general principles and neglect of individual aspects, and their disregard for contextual features have also been criticized (Brown \& Dissanayake, 2009, p. 54; Cela-Conde et al., 2011, p. 46). The attempt to understand the artistic experience by focusing on beauty, pleasure, and visual and auditory images is certainly limiting. To come to grips with the artistic experience, it seems necessary to take into account other important mental states besides pleasure, other basic emotional responses which are not related to happiness and surprise such as fear, anger, disgust, and sadness, and other images apart from the visual and the auditory, such as gustatory, olfactory, and tactile images. Besides, even though the capacity to appreciate beauty seems to be universal, individuals do not always agree on which objects and events are beautiful — something which is closely tied to learnt meaning, which sometimes seems to be ignored in these studies. Here it may be useful to stress that even though attention is firstly motivated by innate preferences, it is also motivated by learnt preferences and goals acquired on the basis of the innate preferences (Damasio, 1994, pp. 185, 198). Moreover, our senses engage memories and prior knowledge, and by means of an associative process, individuals learn to respond emotionally to many other stimuli (Damasio, 2001, pp. 67, 68). Objects and events have therefore different meanings for different individuals, in different contexts, and at different times (Cela-Conde et al., 2011, p. 47). Emotionally competent objects and events acquire thus different meanings and perceptual values as individuals interact with them in terms of what they already know. These learnt emotional responses to the perception of certain formal features of objects and events must be taken to constitute a second level of meaning, or "individual meaning," in the artistic experience.

Be that as it may, the activation of emotional responses to the perception of certain formal features of both universal and learnt meaningful stimuli does not as such constitute an artistic experience. We cannot fully explain this experience by only studying perception and emotion. Even though Starr and Noë pointed out this fact in the debate, they did not seem to come up with an alternative solution. Nonetheless, evolutionary biology, including the embodied and the embedded premises, can begin explaining the artistic experience by shedding light on the cognitive processes underlying it. Pointing out such processes can help us explain why the artistic experience is highly individual, yet universal to human beings, an experience that changes in intensity and varies in duration, as Starr mentions (2013, p. 18), and that certainly includes emotional responses to the perception of universal and learnt meaningful objects and events, as argued above, but that is characterized not by perception and emotion, as often stated, but by particular degrees of imagination and consciousness. 


\section{Imagination and Consciousness}

Rather than perception and emotion, two cognitive capacities that distinguish humans from other species are particular degrees of imagination and consciousness, and these seem to make possible, and underlie, the artistic experience (van Heusden, 2010, p. 159; Wah, 2014, pp. 119-124).

Degrees of imagination, the power of forming, retaining, and manipulating mental images, no matter of how rudimentary a kind, provided that the mental images imply some dim idea of an absent object or event, can be distinguished in the animal kingdom. For instance, mollusca, insecta, arachnida, crustacea, cephalopoda such as octopuses or squids, and cold-blooded vertebrata such as fish or reptiles can recall sensuous associations and retain the memory of a sensation when there is no direct perception of objects and events. Hymenoptera such as ants, bees or wasps, and wild animals such as foxes, wolves, or rabbits can form mental images of absent objects and events suggested by other objects and events. Birds such as eagles, parrots, or canaries, and mammalia such as elephants, horses, dogs, cats, or apes can form mental images of absent objects and events independently of any obvious suggestion proven in their dreaming. Forming, retaining, and manipulating mental images intentionally with the set purpose of obtaining new combinations is distinctively human (Romanes, 1885, pp. 142-153). This possibility to recreate or manipulate mental patterns requires a distinctive degree of consciousness.

In the last two decades, neuroscientific approaches to consciousness have advocated that the biological foundations of conscious experience involve coordinated and synchronized firing between neural patterns belonging to several different and often distant areas in the nervous system (Cela-Conde et al., 2011, p. 41). Consciousness, a physical, private, neural process which influences behavior and involves large populations of neurons engaged in strong and rapid "reentrant" interactions widely distributed in many different regions of the nervous system is associated with biological structures that have evolved over time (Edelman \& Tononi, 2000, pp. 36, 49, 62, 106). The brain stem, interconnected with the whole organism, seems to ground consciousness. Evidence of this has been found in lesion studies. When the upper part of the brain stem is damaged, the result is coma or vegetative state in which consciousness is impaired. By contrast, when the lower part of the brain stem is affected, the result is locked-in-syndrome, which consists of complete paralysis while consciousness is maintained (Damasio, 2011).

Degrees of consciousness can also be distinguished in the animal kingdom. Gerald Edelman and Giulio Tononi distinguish between primary consciousness, the capacity to generate a mental scene for the purpose of directing behavior, and higher-order consciousness which presupposes the existence of primary consciousness, and is accompanied by a sense of self and the ability to construct and integrate past (memory) and future scenes (imagination) (Edelman \& Tononi, 2000, pp. 102-104). Likewise, Antonio Damasio points at two similar levels of consciousness, but he refers to them in different terms. The first is the minimal-scope, essential or core consciousness, being the sense of the here-and-now 
which revolves around the core self, and the second is extended consciousness which directs the autobiographical self and coincides with identity. Degrees of self, or the feeling of one's own existence, can also be distinguished. The nonconscious proto self which characterizes deep sleep, the core self which emerges in core consciousness, and the autobiographical self which is linked to the idea of identity and is based upon the experience of the integration of the here-and-now (perception), with the lived past (memory), and the anticipated future (imagination), so-called "mental time travel" (Damasio, 1999, pp. 17, 174-175; 2003, pp. 177-179; 2010, pp. 168-172; 2011). To explain the origins of consciousness it is important to underline that consciousness has a cumulative and conservative character and that it expands both in evolution and in development. Several degrees of consciousness can be distinguished in humans, from awareness of feelings to complex extended states. These levels emerge and develop during the first ten years of life, with implications for the development of the self and the social and cognitive functioning, and they seem to reflect its evolutionary trajectory (Nelson, [2005] 2012, pp. 116, 124-125). Even though a degree of self-consciousness - that is, self-recognition - has been demonstrated in bonobos, chimpanzees, gorillas, orangutans, elephants, dolphins, and birds (Plotnik et al., 2015; de Waal, 2012), a distinctive degree of self-consciousness seems to characterize humans: self-imagination.

Barend van Heusden explains that human cognition is characterized by the experience of difference between memory and perception, so-called "decoupled cognition." The negative outcome of this experience is that doubts about what humans perceive, about meanings, and about intentions make life a very uncertain affair. However, the positive outcome of this experience is that it liberates humans from the immediacy of perception and emotion, making comparison, imagination, metaphor, and creative reasoning possible. For instance, when one is reading a book, the perception of the text is backgrounded, while imagination is foregrounded. The experience of difference between memory and perception includes both the experience of difference in the environment and the experience of difference between one's own here-and-now, lived past, and imagined future. Humans can deal with their own experience of difference via self-imagination, a human cognitive strategy which implies the acting out or the recreation of one's own or others' situation in the imagination and underlies the artistic experience. Through self-imaginations humans are able to act out or recreate situations that are not identical to or dependent on the situations they actually perceive (van Heusden, 2004, pp. 8, 13-18, 24; 2009, pp. 615-622; 2010, pp. 160-161). Whether self-imagination is related to so-called "default mode network" mentioned in the debate by Starr is still to be researched (Buckner et al., 2008). The fact that self-imaginations build upon one's own memories and perceptions explains why the artistic experience is highly individual.

Merlin Donald proposes a model that can shed light on the origins of this experience. He points out three adaptations in human culture: the mimetic, the mythic and the theoretic. The first adaptation took place around 2 million years ago, and is based on the capacity for planning and the practice of skills through imitation and ritual. The second adaptation occurred around 150,000 years ago, and led to a rapid expansion of culture through language. 
The third adaptation came with so-called theoretic culture, began around 40,000 years ago, and is heavily dependent on media technologies. The progression of these adaptations is cumulative and conservative, which means that the chronology of this model lies in the internal logic of the evolutionary sequence rather than in specific dates. Donald stresses that whereas the first two transitions were dependent upon evolution - the first upon changes in the nervous system and the second upon changes in the vocal apparatus - the third transition was dependent upon the invention and elaboration of external storage devices. According to this theory the first stage enabled mimesis, the foundation skill that defines human cognition and made the artistic experience possible. Behavioral manifestations such as imitation, rehearsal, and non-linguistic gesture are mimetic acts and are the result of the conscious control over action. Their cognitive core is kinematic imagination, that is, the ability to envision one's own body in motion. Even though the cognitive quality that dominates in the experience of the arts is mimesis, the diversity of art today reflects the three cultural domains (Donald, 1991, pp. 269, 273; 2001, pp. 263, 271, 274; 2006, pp. xv, $8-10 ; 2013)$. Archaeological evidence of the earliest degrees of this experience are to be found in 2.5 million year old carved stones, and in 1.5 million year old hand-axes from the early Pleistocene which already reflect degrees of imaginative power, rehearsal of skill, enhanced attention, flexibility of response, and self-awareness (Dutton, 2009; Donald, 2013).

\section{Artistic Experience}

As the study of the artistic experience from the perspective of evolutionary biology began only a couple of decades ago, there is still no conventional use of terms for referring to the cognitive processes underlying this experience. This cognitive strategy has been referred to as "aesthetic imagination" (Dissanayake, 2001), "kinematic imagination" (Donald, 2001), "creative imagination" (Damasio, 2003; Mithen, 2005) "imaginative experience" (Dutton, 2009), "artistic cognition" (Sullivan, 2010) and "self-imagination" (van Heusden, 2010). I will refer to this cognitive process as "reflective imagination" (Wah, 2014) because the use of this term emphasizes the degrees of imagination and consciousness necessary for this process to take place, and because it facilitates the distinction between this cognitive strategy and the objects and events that may be experienced-and which are commonly referred to as "art," "artworks," or "the arts" (Wah, 2014, p. 118).

The artistic experience, be it through making music, singing, dancing, or telling a story by means of pantomime, drawing, pretend play, spoken or written language, is underlain by reflective imagination. This experience derives from self-observation, and as such, it improves the understanding of emotional and social cues, giving the opportunity to explore and try out a variety of emotions and situations. Once one becomes aware of the relation objects and situations have with emotions, one can strive to regulate or control emotional responses, at least to some extent, because one can decide which objects and situations one allows in the environment, and on which objects and situations one lavishes time and attention (Damasio, 2003, pp. 51-52; Dutton, 2009, pp. 106, 122-123; Dutton in Kandel, 2012, pp. 441-443; Kandel, 2012, p. 390). As the artistic experience allows humans to 
recreate events, consider indirect evidence, deduce "what might have been" or "what might come to be," and work out solutions to problems without the actual practice, we may refer to these experiences as self-rehearsals. These are a means to rehearse specific aspects of life, to exercise emotion, empathy, theory of mind or mind reading, that is, to read one's own and others beliefs, desires or intentions, and therefore to solve problems in the imaginary realm. For instance, the experience of storytelling is a low-risk way of dealing with one's own or others' situations in the imagination (Boyd, 2009; Damasio, 2010, p. 296; Dutton, 2009, pp. 106, 113; Gombrich, 1987, p. 211 in Kandel, 2012, p. 13; Kandel, 2012, pp. 393, 442). This self-reflective process is an "organism-environment" adaptation that confers the ability to escape from being stimulus bound, to foresee and evaluate beforehand, to take another's viewpoint, to reflect upon one's own behaviors and actions and their outcomes, and to change those behaviors and actions (Metcalfe, 2008).

A basic function of the artistic experience is to manage life. Humans can deal with the unfamiliar and anticipate reactions through this process of understanding, of signification, of identity construction, both personal and collective, which is reflected upon with gestures, sounds, artefacts, language, diagrams, and structures (van Heusden, 2009, p. 611; 2010, pp. 160-161). Identity constructions are important because they provide orientation and guide behavior and action (Damasio, 2003, p. 208). This is possible because, even though the majority of one's behaviors are nonconscious, feelings are important contributors to behavioral tendencies. Emotional systems coordinate many behavioral processes, but when aroused, those systems are accompanied by feeling states that guide and sustain patterns of behavior and may mediate learning. Because of this, for at least some time, experiences control behaviors (Panksepp, 1998, pp. 9, 15-16). The frontal regions of the central nervous system are concerned with the motor control of behavior and action, which improves self-regulation, and with the ability to perceive oneself as actor, to rehearse, reflect, and shape one's actions creatively, generating novel neural patterns. The fact that the artistic experience arrests attention and generates novel neural patterns enables flexibility of response and a wide range of behavior (Donald, 2006, pp. 2-11, 16-20). By doing so, the artistic experience complexifies consciousness (Csikszentmihalyi, 1988, pp. 63-64; Nelson, 2005). Based upon the innate propensities for mutuality and the feeling of belonging to a group, at its highest degree the artistic experience is characterized by a fleeting loss of self, providing the opportunity to enlarge the individual's sense of being (Disannayake, 2000, pp. 49, 203). Far from being peripheral, dysfunctional, or trivial, the artistic experience is distinctively human and overwhelmingly integral to humankind (Dissanayake, 1992, pp. xvi, xix; Damasio, 2010, p. 294).

Many scientists and humanists understand the artistic experience as entertainment, which is an obstacle that still needs overcoming (Stafford, 2011, p. 5). Yet the artistic experience is not about entertainment, but about self-engagement. The difference between entertainment and the artistic experience is that the former does not imply reflective imagination; that is, one perceives a situation but one does not imagine oneself or others in such situation. From the perspective of this paper it is therefore difficult to give specific or concrete 
examples of "artworks" as the experience of any meaningful object or event, any emotionally competent stimulus, may trigger this cognitive process (Wah, 2014, pp. 132-133). For instance, think of how sometimes while experiencing a certain film, one may feel as if one were playing the role of a character. After this experience takes place, one may feel the urge to act, to take action, or to change a behavior (Wah, 2014, p. 137). As long as one recognizes oneself or others in such a situation, the experience of any emotionally competent stimulus, whether recalled, perceived, or imagined, can trigger this reflective aspect of the imagination. This is possible because memory, perception, and imagination ultimately recruit some of the same neural circuitry (Kandel, 2012, p. 313).

In neural terms, the difference between human memory, perception, and imagination is that memory is the capacity for strengthening the connection between neurons, perception is the capacity for mapping patterns of sensorimotor activity, and imagination is the capacity for retaining, forming, and manipulating these mental patterns (Wah, 2014). Lesion studies and functional imaging suggest that the recall of objects and events depends on the sites engaged in the original perception of these objects and events. The location where memory records are (re)experienced is not that different from the location of the original perceptions (Damasio, 2010, pp. 143, 149). Memory has properties that allow perception to alter recall and recall to alter perception. Every act of perception is, to some degree, an act of creation, and every act of memory is, to some degree, an act of imagination (Edelman \& Tononi, 2000, p. 101). Humans can reliably map states that are actually occurring, but they can also transform body states by recalling, and simulate body states that have not yet occurred by imagining them. Whether they are actually mapped in perception, reconstructed maps recalled from memory, or simulated maps from the imagination, the effect is similar; but the emotional grade or intensity varies. While some stimuli trigger weak, barely perceptible emotional reactions, others evoke strong emotional reactions. Pattern activation is not set, because a number of influences can modulate the activity. Recalling and imagining are therefore approximations rather than replicas, and thus not quite as vivid or accurate as actual perception (Damasio, 2003, pp. 55-59; 2010, pp. 70, 93, 111, 149). This means that the artistic experience may be triggered by the experience of any emotionally competent stimulus, whether recalled, perceived, or imagined; however, the intensity of this experience increases with the actual perception of meaningful objects and events. This explains why the perception of meaningful institutional artworks, which presupposes voluntary attention, may facilitate the triggering of an artistic experience.

To be sure, stimuli that are too short, too weak, or too strong, may be perceived in core consciousness and may lead to an emotional response. These stimuli may be sufficient for sensory detection, produce enough neural activation, and may eventually be retrieved or recognized in extended consciousness. However, if the activation has no highly differentiated patterns, extended conscious experience does not occur. This means that there is a correlation between sustained neural activity and grades of consciousness (Edelman \& Tononi, 2000, pp. 67-70). Thus, at the level of minimal attention and core consciousness the attention is outward-directed, and humans interact with objects and events in terms of what they already know, in terms of memories. In such cases, emotional responses to the 
perception of formal features of both universal and learnt meaningful objects and events are stereotyped or predisposed. By contrast, at the level of enhanced attention and extended consciousness the attention becomes inward-directed, and humans can experience objects and events in terms of self-imaginations. In such cases, responses to the experiences are felt and become flexible (Donald, 2006, p. 5; Wah, 2014, p. 121). This is important for our purposes because the latter is the process which underlies the artistic experience.

From the perspective of this paper, on the one hand, making a distinction between artists and beholders is not necessary, as the experience of reflective imagination is not the exclusive preserve of exceptionally creative individuals, but is equally at work in the mind of any self-engaged beholder (Currie in Roth, 2007, p. xxxiii). It is because of this that the discrete roles of artist and beholder are sometimes not considered outside the Western tradition (Cross, 2007, p. 146). From the point of view of this paper, on the other hand, Starr's proposal to "unify the arts" as a category, that is, to posit a kinship of the arts, becomes a possibility (Starr, 2013, p. 3). This unification would include the arts of all kinds, in all times and places, including the evolutionary past, making possible the exploration of their universality and probable adaptive value (Dissanayake, 2015). With this form of self-reflection, and via imagination, humans can reflect upon themselves, upon others, and upon the environment (van Heusden in Schaik, 2010). This explains why "art unveils us to ourselves," the quote mentioned by Noë in the debate with the only purpose of dazzling his audience, as he himself stated. The purpose of this paper is, however, to contribute to an explanation of why the artistic experience affords to do so by pointing out the cognitive processes underlying this experience.

\section{Conclusion}

In this paper I have argued that, in contrast to what Starr and Noë discussed in the debate "Can neuroscience help us understand art?", aesthetics is not what characterizes the artistic experience. The cognitive processes which underlie the artistic dimension of an experience are not perception and emotion, as often stated, but particular degrees of imagination and consciousness. I refer to this cognitive strategy as reflective imagination (Wah, 2014), a strategy which may be triggered by the experience of not only institutional art but any emotionally competent stimulus, whether recalled, perceived, or imagined. The fact that distinctive degrees of imagination and consciousness underlie the artistic experience explains why this experience is characteristically human and universal to human beings. The fact that self-imaginations build upon one's own memories and perceptions explains why this experience is highly individual.

Finally, to answer the debate's main question, I consider that neuroscience can certainly help us understand art, for it reveals conscious and unconscious cognitive functions and sheds light on the biology of attention, memory, emotion, perception, imagination, and consciousness. The primary aim is, however, not to quantify emotional responses to the perception of specific examples of institutional artworks, find their neural correlates, or 
visualize them on the basis of neuroimaging techniques. As experiences are embodied and embedded, they do not have clear temporal boundaries, and can hardly be translated into data points. By contrast, the primary aim of studying the artistic experience, I suggest, is to investigate the cognitive processes underlying it in order to understand its basic functions, and therefore its value for the human species.

\section{References}

Arnheim, R. (1954). Art and visual perception: A psychology of the creative eye. Berkeley: University of California Press.

Arnheim, R. (1969). Visual thinking. Berkeley: University of California Press.

Boyd, B. (2009). On the origin of stories evolution, cognition, and fiction. Cambridge, MA: Belknap Press of Harvard University Press.

Brown, S., \& Dissanayake, E. (2009). The arts are more than aesthetics and aesthetics is more than art: Neuroaesthetics as narrow aesthetics. M. Skov, O. Vartanian (Eds.), Neuroaesthetics (pp. 43-57). Amityville, NY: Baywood.

Buckner, R. L., Andrews-Hanna, J. R., \& Schacter, D. L. (2008). The brain's default network anatomy, function, and relevance to disease. Annals of the New York Academy o Sciences, 1124(3), 1-38.

Cela-Conde C. J., Agnati L., Huston J. P., Mora F., \& Nadal M. (2011). The neural foundations of aesthetic appreciation. Progress in Neurobiology, 94(3), 39-48.

Chatterjee, A. (2013). The aesthetic brain: How we evolved to desire beauty and enjoy art. Oxford, UK: Oxford Scholarship Online.

Cross, I. (2007). Music, science, and culture. In I. Roth (Ed.), Imaginative minds (pp. 147-168). Oxford, UK: Oxford University Press.

Csikszentmihalyi, M., Csikszentmihalyi, I. S. (Eds.). (1988). Optimal experience: Psychological studies of flow in consciousness. New York, NY: Cambridge University Press.

Damasio, A. (1994). Descartes' error: Emotion, reason, and the human brain. New York, NY: Putnam.

Damasio, A. (2000). The feeling of what happens: Body, emotion and the making of consciousness. London, UK: Vintage.

Damasio, A. (2001). Some notes on brain, imagination and creativity. In K. H. Pfenninger \& V. R. Shubik (Eds.), The origins of creativity (pp. 59-68). Oxford, UK: Oxford University Press.

Damasio, A. (2003). Looking for Spinoza: Joy, sorrow, and the feeling brain. Orlando, FL: Harcourt.

Damasio, A. (2010). Self comes to mind: Constructing the conscious brain. New York, NY: Pantheon Books.

Damasio, A. (2011). The quest to understand consciousness [TED Lecture]. Retrieved February 2015 from http://www.ted.com/speakers/antonio_damasio 
Di Dio, C., \& Gallese, V. (2009). Neuroaesthetics: A review. Current Opinion in Neurobiology, 19(6), 682-687.

Dissanayake, E. (1995). Homo aestheticus: Where art comes from and why. Washington, WA: University of Washington Press.

Dissanayake, E. (2000). Art and intimacy: How the arts began. Washington, WA: University of Washington Press.

Dissanayake, E. (2015). 'Aesthetic primitives': Undamental biological elements of a naturalistic aesthetics. Aisthesis: Pratiche, linguaggi e saperi dell'estetico, 8(1), 6-24.

Donald, M. (1991). Origins of the modern mind: Three stages in the evolution of culture and cognition. Cambridge, MA: Harvard University Press.

Donald, M. (2001). A mind so rare: The evolution of human consciousness. New York, NY: Norton.

Donald, M. (2006). Art and cognitive evolution. In M. Turner (Ed.), The artful mind: Cognitive science and the riddle of human creativity (pp. 4-20). New York, NY: Oxford University Press.

Donald, M. (2013). Mimesis theory re-examined, twenty years after the fact. Evolution of mind, brain, and culture, 7, 169-172.

Dutton, D. (2009). The art instinct: Beauty, pleasure, and human evolution. New York, NY: Bloomsbury Press.

Edelman, G. M., \& Tononi G. (2000). A universe of consciousness: How matter becomes imagination, New York, NY: Basic Books.

van Heusden, B. P. (2004). A bandwidth model of semiotic evolution. M. Bax et al. (Eds.), Semiotic evolution and the dynamics of culture (pp. 3-33). Bern, Switzerland: Peter Lang.

van Heusden, B. P. (2009). Semiotic cognition and the logic of culture. Pragmatics and Cognition, $17(3), 611-627$.

van Heusden, B. P. (2010). Estrangement and the representation of life in art. In A. van den Oever (Ed.), Ostrannenie: On 'strangeness' and the moving image: The history, reception, and relevance of a concept (pp. 157-164). Amsterdam, the Netherlands: Amsterdam University Press.

Hyman, J. (2010). Art and neuroscience. In R. P. Frigg \& M. C. Hunter (Eds.), Beyond mimesis and convention: Boston studies in the philosophy of science (pp. 245-261). Springer.

Kawabata, H., \& Zeki, S. (2004). Neural correlates of beauty. Journal of Neurophysiology, 91(4), 1699-1705.

Kandel, E. R. (2012). The age of insight: The quest to understand the unconscious in art, mind and brain from Vienna 1900 to the present. New York, NY: Random House.

LeDoux, J. (1996). The emotional brain: The mysterious underpinnings of emotional life. New York, NY: Simon and Schuster.

Metcalfe, J. (2008). Evolution of metacognition. In J. Dunlosky \& R. Bjork (Eds.), Handbook of metamemory and memory (pp. 29-46). New York, NY: Psychology Press. 
Nelson, K. (2012). Emerging levels of consciousness in early human development. In H. S. Terrace \& J. Metcalfe (Eds.), The missing link in cognition: Origins of self-reflective consciousness (pp. 117-141). Oxford, UK: Oxford University Press.

Noë, A. (2009). Out of our heads: Why you are not your brain, and other lessons from the biology of Consciousness. New York, NY: Hill and Wang.

Panksepp, J. (1998). Affective neuroscience: The foundations of human and animal emotions, New York, NY: Oxford University Press.

Plotnik, J. M., de Waal, F. B. M., Moore, D., \& Reiss, D. (2010). Self-recognition in the Asian elephant and future directions for cognitive research with elephants in zoological settings. Zoo Biology, 29(2), 179-191.

Ramachandran, V., \& William, H. (1999). The science of art: A neurological theory of aesthetic experience. Journal of Consciousness Studies, 6(6-7), 15-51.

Romanes, G. J. (1885). Mental evolution in animals. London, UK: Kegan Paul, Trench, \& Co.

Roth, I. (2007). Imaginative minds. Oxford, UK: Oxford University Press.

van Schaik, J. (2010, November). Kunst is een gegeven, interview met Barend van Heusden. Dagblad van het Noorden.

Starr, G. (2013). Feeling beauty: The neuroscience of aesthetic experience. Cambridge, MA: The MIT Press.

Stafford, B. M. (2011). A field guide to a new meta-field: Bridging the humanities, neurosciences divide. Chicago, IL: University of Chicago Press.

Sullivan, G. (2010). Artistic cognition and creativity. In H. Karlsson \& M. Biggs (Eds.), The Routledge companion to research in the arts (pp. 99-117). New York, NY: Routledge.

Tooby, J., \& Cosmides L. (2001). Does beauty build adapted minds? Toward an evolutionary theory of aesthetics, fiction and the arts. SubStance, 94-95, 6-26.

Wah, A. (2014). Reflective imagination: A hybrid cognitive process. In The meaning is the message: An inquiry into new media, cognition, and reflective imagination (pp. 116-137). (Doctoral dissertation). University of Groningen, the Netherlands.

de Waal, F. B. M., \& Ferrari P. F. (2012). The primate mind: Build to connect with other minds. Cambridge, MA: Harvard University Press.

Zeki, S. (1999). Inner vision: An exploration of art and the brain. Oxford, UK: Oxford University Press. 